\title{
Abstracts of Papers in English
}

RESERVOIR OPERATION FOR WATER QUANTITY AND QUALITY USING ADAPTIVE NEURO-FUZZY INFERENCE SYSTEMS (ANFIS) AND GENETIC ALGORITHMS

\author{
F. Soltany \\ R. Kerachian \\ M. Karamouz \\ Center of Excellence for Engineering and \\ Management of Infrastructures \\ University of Tehran
}

Key Words: reservoir operation, genetic algorithms, water quality, ANFIS.

\section{Abstract}

In this study, an algorithm combining a GA-based optimization model and a water quality simulation model is developed for determining reservoir operating policies, considering water quality issues.

To reduce the run time of the GA-based optimization model, a trained Adaptive Neuro-Fuzzy Inference System (ANFIS) is used for water quality simulation in a reservoir. The main problem is also decomposed to a long-term and an annual optimization model and it is shown that the proposed model does not reduce the accuracy of the reservoir operating policies. The reliability of the water supply is considered to be the objective function in the long-term stochastic optimization model. The operating rules obtained using this long-term model provide the time series of the optimum reservoir water storages at the beginning and end of each water year. In the next step, these optimal reservoir storage values are considered as constraints for annual reservoir operation optimization models (annual models), whose objectives are related to the allocated water quantity and quality. The proposed model is applied to the 15 -Khordad Reservoir in the central part of Iran.

\section{NEURAL NETWORK APPROACH IN MODE CHOICE MODELING}

\author{
M. Ferasat \\ M. Kermanshah \\ Dept. of Civil Engineering \\ Sharif University of Technolgy
}

Key Words: mode choice model, artificial neural network model, Logit model, Pricing central zone areas.

\section{Abstract}

Pricing policy is a method for controlling air pollution in urban central areas. The policy can be implemented on a daily basis, in such a way that the pollution level is kept close to its standard level. The ultimate goal of such a research can be the evaluation of a pricing policy for Tehran central zone areas by means of a set of mode choice models. Stated preference base mode choice models have been developed using the neural network concept; as an alternative to the existing choice model approach. Then, the models were compared with another set of models developed by the logit structure, based on 
the "percent of correct prediction" criterion. A rather marginal superiority of models based on the neural network approach can be reported.

\section{LONGTERM PRECIPIDATION FORECASTING USING CLIMATE SIGNALS CLUSTERING WITH RESPECT TO PRECIPITATION VARIATIONS WITH MODIFIED K-MEANS METHOD (CASE STUDY: PRECIPIDATION FERECASTING OF SISTAN-BALOUCHESTAN PROVINCE)}

B. Zahraie

Center of Excellence for Engineering and Management of Infrastructures

University of Tehran
A. Roozbahani
School of Civil Engineering
University of Tehran

Key Words: clustering, climate signals, modified K-Means, GA clustering, sea surface temperature (SST).

\section{Abstract}

Studying climatic variations and finding different hydrological variables, such as precipitation, can be very useful in the prediction of these variables. Some recent research has tried to explain the relation between large scale climate signals, like Sea Surface Temperature (SST), and some hydrological variables, such as precipitation. In this paper, a novel method for clustering is presented, which is called "Modified K-Means". This method is based on the ordinary K-Means method, but the framework of selecting the cluster centers is modified in a way wherein clustering SST and its relation with precipitation are considered simultaneously. This model tries to find the relationship between climatic signals and precipitation variations. 20 rain gauges in the Sistan \& Baluchestan province in Southeastern Iran have been considered in the case study. The use of the Modified KMeans method for showing the relation between precipitation in various seasons and temporal-spatial variations of SST is an innovative aspect of this paper.

CONSTRUCTION AND DEMOLITION WASTE PRODUCTION AND MANAGEMENT IN DEVELOPING COUNTRIES (A CASE STUDY: TEHRAN METROPOLITAN, IRAN)
M. M. Mortaheb

Dept. of Civil Engineering

Sharif University of Technology

A. Kavousian

Dept. of Civil Engineering

Stanford University

Key Words: management, construction waste.

\section{Abstract}

The construction industry is one of the most important sectors of economy in developing countries. This industry consumes enormous amounts of raw material and produces considerable waste. The optimization of construction material usage not only saves costs, but, also, can significantly contribute towards sustainable development. This article addresses construction waste management as an approach to improve construction productivity, with a focus on its application in developing countries. The status of construction waste production and management in Tehran metropolitan, Iran-as a developing country-is investigated and compared with the status of developed countries. Subsequently, barriers to implement concepts of construction waste management in Iran are addressed. Based on the findings of this study, it is shown that, in order to implement construction waste management in Iran's construction industry, the government should set rules and provide instructions on the issue; while constructors must design structures for minimum waste, and adopt modern construction methods, like prefabrication.

\section{SEISMIC HAZARD ASSESSMENT OF IMAM REZA (PEACE BE UPON HIM) HOLY SHRINE REGION}

\author{
G. Ghodrati Amiri
}

S.A. Razavian Amrei

Dept. of Civil Engineering

Iran University of Science and Technology

S.R. Pashanejati

Building and Housing Research Center Tehran

Key Words: seismic hazard assessment, seismic parameters, horizontal acceleration, vertical acceleration, mashhad, Imam Reza (peace be upon him)'s holy shrine.

\section{Abstract}

The objective of performing this research is to analyze the earthquake hazard and to provide the iso-acceleration maps for different seismic hazard levels in the area of Imam Reza's (Peace Be upon Him) holy shrine. Since the construction in the vicinity of the holy shrine goes back fifty years, and some structures are historical and religious, in order to properly design and optimize the 
historical places, it is needed to provide the design acceleration in different seismic hazard levels. So, by using different resources, the catalogue of the seismicity data; in the radii of 150 and $200 \mathrm{~km}$ of the area, have been collected and, then, the seismicity parameters have been computed by the Kijkio method. The seismicity parameters of the provinces, which have been presented by Mirzaei \& et al., have been used. Then, the faults of the region have been detected and modeled and, by using the proper attenuation relationships and SEISERISK III software, the values of the acceleration at different levels are computed and the coefficients of the logic tree are applied. Finally, the iso-acceleration maps are resulted.

\section{AN ANALYTICAL AND EXPERIMENTAL STUDY ON THE DUCTILITY OF STEEL RINGS}

R. Abbasnia

Dept. of Civil Engineering

Iran University of Science and Technology

M. G. Vetr

International Institute of Earthquake

Engineering and Seismology

R. Ahmadi

Dept. of Civil Engineering

Zanjan University

M. A. Kafi

Dept. of Civil Engineering

Semnan University

Key Words: ductility, experimentally, steel ring, brace.

\section{Abstract}

Concentric braces are used widely in steel structures, due to ease, low implementation cost and reconstruction speed. In the last two decades, these benefits have created prime research incentives to increase their ductility. The usage of dutiable elements is one of the methods to increase ductility. In this article, a steel ring is used as a dutiable element. The extent of energy absorption and ductility is studied both analytically and experimentally. A steel ring can be welded to two steel plates and can easily be installed within concentric braces. The loading capacity of the steel ring is a function of its length, radius, thickness and yield stress. This property can be used to design a suitable ring, compliant to brace capacity. Results obtained show a high level of energy absorption and a good ductility for the steel ring.

\section{QUANTITY CONTROL OF GEOTECHNICAL PROPERTIES FOR}

\section{GROUND IMPROVEMENT BY CPT AND CPTu RESULTS}

\author{
A. Eslami \\ Dept. of Civil Engineering \\ Amirkabir University of Technology \\ M. Mehrdad \\ M. Khosravi \\ Dept. of Civil Engineering \\ University of Guilan
}

Key Words: ground improvement, quantity control, cone penetration test (CPT), cone tip resistance, pore pressure.

\section{Abstract}

In order to control and evaluate the adequacy of soil stability, the cone penetration test and the comparison of cone tip resistance, friction resistance and pore water pressure, before and after improvement processing, are used. In the present research, different methods of determining important geotechnical parameters, using CPT data, were discussed. 23 sites, including 18 sites with granular soil and 5 sites with fine soil, have been studied, in which the cone penetration test was performed, after and before ground improvement. For control the improvement quantity, after analyzing the measured CPT data, important geotechnical parameters, such as relative density, overconsolidation ratio, friction angle, undrained shear strength, shear wave velocity, Janbu modulus number, Young's modulus and the coefficient of earth pressure at rest, were determined. A comparison of the suggested results showed good agreement with the results of other work and, therefore, one is enable to assess different aspects of ground modification.

\section{AN ALGORITHM FOR SOLVING SPACE CONFLICTS IN SITE CONSTRUCTION}

F. Hadjikhani

Science and Research Branch

Azad University

M. Mofid

Dept. of Civil Engineering

Sharif University

F. Amirghiasvand

Dept. of Computer Sciences

Tehran University

P. Mohammadi

Dept. of Industrial Engineering

Amirkabir University of Technology

Key Words: construction management, building project, space interaction, algorithm. 


\section{Abstract}

Ignorance of modern and scientific techniques, besides the lack of accurate and systematic management and the use of conventional methods, are the reasons behind much lower efficiency in the construction industry compared to developed countries. Selecting construction methods, scheduling activities, and planning the use of site space are the keys to constructing a project efficiently. During the construction process, a limited site will be occupied by a great number of temporary workers and facilities, as well as permanent ones. Since the limitation of workspace will greatly affect efficiency and the project critical path, it is important to precisely organize the available space to minimize conflict in the workshop (construction site) and the reduction of project costs. Site layout and activity scheduling have been tackled as independent problems, whose interdependence is often ignored at the planning stage and which causes many critical problems. In this paper, a method of space scheduling has been proposed, using mathematical sciences, management, conservation and computer programming.

\section{PRINCIPAL COMPONENT ANALYSIS APPLIED TO SEISMIC HORIZON INTERPRETATIONS}

\author{
H. Sabeti \\ Mineral Group \\ Birjand University of Technology
}

A. Javaherian
Dept. of Petroleum Engneerin

Amirkabir University of Technology

B. N. Araabi

Dept. of Electrical and Computer Engineering University of Tehran

Key Words: singular value decomposition, PCA, eigenvalue, eigenvector, seismic horizon picking.

\section{Abstract}

One of the most important stages in seismic interpretation is picking especial horizons in order to detect their underground downward and upward movements in an oilfield. Background noise, however, causes many difficulties to this end. Considering a narrow window of a seismic section, whose reflectors are nearly horizontal, and applying a multivariate statistical method called the Principal Component Analysis, we find the largest eigenvalue that has the most contribution to the variance of data. Lower eigenvalues are subject to noise. Projecting data onto an eigenvector associated with the largest eigenvalue, we obtain a trace with sharper peaks and troughs. This method is applied to two synthetic models; horizontal reflectors and anticline. We, also, examine the window length and dominant frequency of the seismic wavelet. Obtained trace with significantly attenuated noise can be used for tracking weak horizons in a seismic section with a signal-to-noise ratio of 0.2 . Dominant frequency cannot change the result considerably. Optimum window length is the area in which reflectors are horizontal. It is also applied to the real data of an oilfield in S.W. Iran. The obtained results were useful in picking some important horizons. 